\title{
Oestrous intensity is positively associated with reproductive outcome in high-producing dairy COWS
}

\author{
Emanuel Garcia, Jan Hultgren, Pontus Fallman, Johanna Geust, Bo Algers, George Stilwell, \\ Stefan Gunnarsson and Heriberto Rodriguez-Martinez
}

\section{Linköping University Post Print}

N.B.: When citing this work, cite the original article.

Original Publication:

Emanuel Garcia, Jan Hultgren, Pontus Fallman, Johanna Geust, Bo Algers, George Stilwell, Stefan Gunnarsson and Heriberto Rodriguez-Martinez, Oestrous intensity is positively associated with reproductive outcome in high-producing dairy cows, 2011, Livestock Science, (139), 3, 191-195.

http://dx.doi.org/10.1016/j.livsci.2011.01.004

Copyright: Elsevier http://www.elsevier.com/

Postprint available at: Linköping University Electronic Press http://urn.kb.se/resolve?urn=urn:nbn:se:liu:diva-69980 
Oestrous intensity is positively associated with reproductive outcome in high-producing dairy cows

Emanuel Garcia ${ }^{\mathrm{a}, 1}$, Jan Hultgren ${ }^{\mathrm{a}}$, Pontus Fällman ${ }^{\mathrm{a}}$, Johanna Geust ${ }^{\mathrm{b}}$, Bo Algers ${ }^{\mathrm{a}}$, George 5 Stilwell $^{\mathrm{c}}$, Stefan Gunnarsson ${ }^{\mathrm{a}} \&$ Heriberto Rodriguez-Martinez ${ }^{\mathrm{a}, \mathrm{d}^{*}}$

${ }^{\mathrm{a} D e p a r t m e n t}$ of Animal Environment and Health, Swedish University of Agricultural Sciences, SE-532 23 Skara; 'bötcenter Viken, Vikens Egendom, SE-521 91 Falköping, Sweden; ${ }^{c}$ Centro de Investigação Interdisciplinar em Sanidade Animal, Universidade Técnica 10 de Lisboa, 1300-477 Lisboa, Portugal; and ${ }^{\mathrm{d} *}$ Department of Clinical and Experimental Medicine, Linköping University, SE-581 85 Linköping, Sweden.

${ }^{1}$ Current address: Hospital Veterinário do Algarve, R. Cidade de Bolama, Lt. B - Lj. A/B, 8000-249 Faro, Portugal

15

*Corresponding author: H. Rodríguez-Martínez, Department of Clinical and Experimental Medicine, Faculty of Health Sciences, Linköping University, SE-581 85 Linköping, SWEDEN. Phone: +46-(0)10-1032284,Fax: +46 (0)101034789, e-mail: heriberto.rodriguezmartinez@liu.se. 


\begin{abstract}
This study tested whether strong oestrus symptoms are linked to low lameness score, acceptable pregnancy and calving rates in heifers and first parity dairy cows with a high genetic potential for milk production. In a single Swedish nucleus herd for genetic selection and testing, oestrous intensity was determined by detailed observations of 67 females, balanced in terms of age and breed (37 heifers and 30 first-parity cows; 32 Swedish Red cows and 35 Swedish Holsteins). Animals were inseminated with semen of proven quality on the day of detected oestrus. Pregnancy was diagnosed on day 50 by trans-rectal palpation. More heifers than cows exhibited a strong standing oestrus (46 vs. $10 \%, \mathrm{P}<0.05$ ). The pregnancy rate at day 50 was higher among heifers than cows (72 vs. $37 \%, \mathrm{P}<0.01)$, as well as the calving rate $(64$ vs. $33 \%, \mathrm{P}<0.05)$. Standing oestrus was associated with 4.6 to 4.8 -fold higher odds of pregnancy and calving, compared to weaker or solely secondary oestrous signs. Lameness decreased the odds of pregnancy 5.1 times and of calving 3.5 times, but no significant association between lameness and oestrus intensity was found. In conclusion, intensive oestrus signalling and non-lameness relate to high reproductive performance in high-producing dairy cattle.
\end{abstract}

Keywords: oestrous intensity, lameness, fertility, dairy cattle 
Between 1997 and 2007, world milk production increased by 27\% (122 million tonnes; International Dairy Federation, 2008), although the number of milk producing cows dropped. High milk production can negatively affect animal welfare (European Food Safety Authority [EFSA], 2009b; Oltenacu and Algers, 2005), compromising cow robustness and threatening ethically and economically - the sustainability of the dairy sector (Rodriguez-Martinez et al., 2008).

Lameness is a major sign of poor welfare in dairy cows (Bell et al., 2009; EFSA, 2009a; Farm Animal Welfare Council, 1997; Haskell et al., 2005), with direct effects on reproduction. Lameness is still highly prevalent in the UK, Denmark and the USA (reviewed by Hultgren et al., 2004; Bell et al., 2009), in contrast to Sweden, where a much lower prevalence of lameness at claw trimming $(\sim 5 \%)$ was found, with lactation incidence risks of $\sim 2 \%$ (Manske et al., 2002).

EFSA (2009b) concluded that reproductive disorders are associated with animal welfare by reflecting prolonged or short-term reduced welfare (anoestrus due to production-related stress). Not surprisingly, a large Swedish survey ranked reproductive performance as a useful indicator of good animal welfare status in dairy herds (Hallén Sandgren et al., 2009). Optimal 60 behavioural display of oestrus ought to indicate the level of well-being among animals (Farm Animal Welfare Council, 2009). However, Welfare Quality (2009) did not include reproductive performance or expression of oestrus as criteria for on-farm welfare assessment. This apparent discrepancy might relate to different conceptual interpretations of the relevance of oestrous signalling for animal well-being. 
One of the pre-requisites for optimal reproductive performance is the evident behavioural display of oestrus. Full oestrous display, central in reproductive management, signals not only sexual receptivity for mating (standing behaviour), but also the imminence of spontaneous ovulation, facilitating proper timing for artificial insemination (AI) and, theoretically, 70 successful fertilization. In modern dairy farming, signs of standing oestrus are not displayed by more than $50 \%$ of the cows in oestrus (van Eerdenburg et al., 2002). Thus, where AI is replacing natural mating, farmers need to record true oestrus accurately, and not only rely on indirect indicators (reviewed by Rodríguez-Martínez et al., 2008) This calls for studies of factors influencing oestrous behaviour, such as milk yield, lameness, social status, and

75 interaction with herd mates (Diskin, 2008a; reviewed by van Eerdenburg et al., 2002). If the oestrous behaviour of a bovine is compromised by any of the above factors, or their concerted action, its ability to reproduce might be constrained.

The objective of the present study was to study relationships between oestrous symptoms,

80 lameness, pregnancy and calving rates in dairy heifers and first-parity cows with a high genetic potential for milk production. We hypothesized that both strong signalling of oestrus and non-lameness are associated with acceptable pregnancy and calving rates, and that lameness is associated with weak oestruses. 


\section{Material and methods}

\section{Farm facility and animals}

The study was carried out at the dairy farm Nötcenter Viken (NCV) in Falköping, Sweden

(58N 15' 99.71" 13E 59' 63.70"). The NCV is dedicated to feed trials, embryo production using a multiple-ovulation embryo transfer (MOET) programme, and to selection of AI-bull mothers. The dairy herd consisted of $\sim 1,000$ heads, including $\sim 400$ Swedish Red (SR) and Swedish Holstein (SH) cows of various parities and 200 heifers. The NCV operated on a loose-housing system consisting of cubicles equipped with rubber mattresses and concretebased walkways coated with rubber-mats (cows) or not (heifers). Cows were kept in two different parks, separated by breed; whereas heifers were distributed in three contiguous parks in another building. No bulls were present on the farm. The animals were in-house, except for the compulsory summer grazing period from May to September. Milking took place three times per day $(0500$ h, 1300 h, 2000 h) in a rotary milking parlour (DeLaval, Stockholm, system, 1998) with rations composed of grass silage, cereal grains, sugar beet by-products, and heat-treated rapeseed or soybean meal (Murphy, 2004). Minimum age for first AI was 15 months, and the voluntary waiting period after calving was 50 days. Heat detection was done routinely by NCV AI technicians using automatic ALPRO ${ }^{\mathrm{TM}}$ activity recording (DeLaval, tour within all animal groups, including cows in the milking parlour. A total of 37 heifers and 30 first-parity cows of either SR or SH breed were included in the study (see Table 1), varying in body condition, time from parturition, and number of previous AIs. 
The study was performed between 13 March and 27 May, 2009. Within this period, females identified by one of the four AI-technicians to be in oestrus were selected for AI and included in the study, each animal contributing with only one record of AI and a possible pregnancy; i.e. animals repeating oestrus did not re-enter the study. The day of AI was defined as day 0 .

The semen used was from progeny-tested sires, selected based on their genetic background and breeding goals (VikingGenetics, Skara, Sweden), using a standard protocol for thawing (in water at $35^{\circ} \mathrm{C}$ for 12 seconds), and $\mathrm{AI}$ (semen deposited in the uterine body). The AI was done on the same day oestrus was detected, up to $1400 \mathrm{~h}$. Milk production records were retrieved until 2 June 2009.

On day 0 , signs of oestrus were further explored visually by one and the same independent observer (non-NCV personnel) for one hour, scoring for presence of mucous vulvar discharge, flehmen reflex, restlessness, licking or sniffing of the perineal region, butting, chin resting, mounted but not standing, mounting other cows (or attempt), and of standing heat.

125 Each sign was registered as absent or present. Restlessness was considered present when the cow showed a high activity according to ALPRO recordings or at visual observation. Signs of oestrus were scored (adapted from van Eerdenburg et al., 2002) as being of low intensity (not being mounted and not standing), medium intensity (being mounted but not standing) or high intensity (standing steadily when mounted). Oestrus intensity (OI) scores were complemented

130 with information from the AI technicians regarding ease of $\mathrm{AI}$, and visible metaoestrus bleeding. Body condition score (BCS) was assessed on day 7 using a 5-point scale with 0.5 increments (adapted from Edmonson et al., 1989) revised by digital images taken from the rear of the cow at a 0 to $20^{\circ}$ angle relative to the tail head as described by Ferguson et al. (2006). Lameness was scored on day 7, based on posture while standing and walking (Walker

135 et al., 2008), as not-lame (levelled back both walking and standing) or lame (arched back when walking or standing, being further characterized as moderately lame or severely lame). 
All inseminated animals were checked visually for non-return to oestrus day 18 to 23 . Animals not returning to oestrus were checked for pregnancy by trans-rectal palpation on day 50. Events were recorded during pregnancy until calving. The study was approved in advance by the local Ethics Committee on Animal Research (Dnr 123-2008, Gothenburg, Sweden), assuring compliance with EC Directive 86/609/EEC for animal experiments.

\section{Statistical analysis}

The data were analysed using the SAS statistical package, version 9.1 for Windows (SAS

145 Institute Inc., Cary, NC, USA). Spearman rank correlation was used to determine relationships between variables. Differences in mean values and proportions were respectively examined with $t$-test (age, BCS) and Fisher's exact test (animal category, breed, OI, lameness, pregnancy and calving rates) while the Kruskal-Wallis test was used for pair-wise comparisons. Odd ratios were derived from a contingency table. Differences of $\mathrm{P}<0.05$ were considered statistically significant.

\section{Results}

The distribution of studied animals by breed, age, BCS, and prevalence of lameness is shown in Table 1. Both animal categories and both breeds were almost equally represented. Mean ( \pm SD) BCS was higher in heifers than in cows $(3.4 \pm 0.4$ vs. $2.8 \pm 0.4$ points) without differing between breeds $(\mathrm{P}=0.0532)$. The prevalence of lameness was higher among cows than among heifers $(59$ vs. $3 \%, \mathrm{P}<0.001)$. Mean $( \pm \mathrm{SD})$ milk production for the cows within the study period was $33.4 \pm 5.2 \mathrm{~kg} /$ day.

Low, medium or high oestrous intensity (OI) was shown by 33 (49\%), 14 (21\%) or 20 (30\%) of the animals at day 0. A high OI was more often seen among heifers than cows (17/37 vs. 3/30, $\mathrm{P}<0.01$ ). For a low $\mathrm{OI}$, however, there was no difference between animal categories. 
165 Out of 67 animals, 66 were observed in oestrus and inseminated. Overall pregnancy rate at day 50 was 56\% (37/66 animals), while overall calving rate reached 50\% (33/66 animals). Up to $80 \%$ of the animals depicting a high OI became pregnant, compared to $45 \%$ of those with a low $\mathrm{OI}(\mathrm{P}<0.05)$ and $46 \%$ of those with a medium OI (not significantly different from high or low). A higher OI related significantly to pregnancy (Figure 1) (Spearman $\mathrm{r}=0.28, \mathrm{P}<0.05$ ).

170 Compared to a low or medium intensity, a high oestrous intensity was associated with 4.6- to 4.8-fold higher odds of pregnancy and calving. As expected, heifers had a higher pregnancy rate than cows, $72 \%$ vs. $37 \%(\mathrm{P}<0.01)$, a difference that was maintained for calving rates (64\% vs. 33\%; $\mathrm{P}<0.05)$. Considering first-parity cows, the older the animal, the lower the oestrous intensity (Spearman $\mathrm{r}=-0.42, \mathrm{P}<0.05$ ). As depicted in Figure 2, lameness intensity 175 and OI were not significantly associated, but increased lameness was related to fewer pregnancies (Spearman $\mathrm{r}=-0.37, \mathrm{P}<0.01$ ) and fewer calvings (Spearman $\mathrm{r}=-0.29, \mathrm{P}<0.05$; Figure 3 ). The odds of not-lame animals becoming pregnant and calving were 3.5 - to 5.1-fold higher than for lame females. 


\section{Discussion}

The present study determined the presence of associations between intensity of oestrus signs and absence of lameness with pregnancy-to-term outcome after AI in Swedish Holstein or

Swedish Red heifers and first parity cows with high genetic potential for milk yield, reared in a single nucleus herd under same management and feeding routines. Overall pregnancy and calving rates were acceptable, with heifers having higher rates than cows. A strong oestrous signalling was reflected in high pregnancy and calving rates and not-lame animals were more likely to become pregnant and calve than lame animals.

The complete behavioural repertoire of oestrous display was observed. Oestrous intensity was classified as low (slight signs) in almost half of the studied sample; while the other half, accounted for a medium (mounted but not standing; mounting) or high (standing oestrus) intensity (21 and 30\%, respectively). The low display of oestrous symptoms might constitute

195 a threat to fertility, especially if detection of oestrus is not optimized. Since the van Eerdenburg et al. (2002) scoring system (used here, albeit with slight modifications) clearly evidenced differences between heifers and cows, it would be advisable to include it as a routine at $\mathrm{NCV}$

The higher the OI, the higher the pregnancy and calving rates achieved. This finding is in agreement with van Eerdenburg et al. (2002), who found a shorter interval to ovulation $(<24 \mathrm{~h})$ in cows with a stronger oestrus. In the present study, pregnant animals scored higher than non-pregnant ones, clearly indicating that standing oestrus (as a token for full physiological display) is still the best behavioural marker for successful AI. Lower intensity oestrus has been associated with delayed ovulation, reduced pre-ovulatory oestradiol $\left(\mathrm{E}_{2}\right)$ concentration and poorer oocyte quality (Cutullic et al., 2009). Additionally, Pérez-Marín and 
España (2007) reported delayed or silent oestrus, along with ovarian disorders and very low pregnancy rates, in repeat breeder Holstein cows.

210 Oestrous behaviour might not be the best marker to predict ovulation time (Forster et al., 2007). Nonetheless, if detection of oestrus in the present study had been based solely on secondary oestrous signs, pregnancy results would still be considered "acceptable": $45 \%$ pregnancy after a low intensity of oestrus vs. $46 \%$ after a medium intensity. This fact should be highlighted in the context of modern dairy farming, where expression of oestrus has been decreasing over decades, particularly for the Holstein breed (Rodriguez-Martinez et al., 2008). Consequently, besides activity measurements, several authors have recently confirmed the importance of using secondary oestrous signs for breeding decisions (Roelofs, 2005; van Eerdenburg et al., 2002; Yoshida and Nakao, 2005). However, this is a very defensive approach, and deemed to enhance current problems, because a poor display of oestrous signs will ultimately affect reproductive performance. This is not surprising, since reproductive performance comprises a set of physiological processes that must be optimal in concert to ensure the birth of a healthy calf. In the present study, oestrous intensity was lower in cows compared to heifers, confirming the negative influence that high milk yield imposes, particularly among first-calvers (reviewed by Rodríguez-Martínez et al., 2008, and references therein).

Reproductive performance is related to animal welfare in dairy herds (Hallén Sandgren et al., 2009). Full display of oestrus signs is the primary reproductive process and ought to be useful as an indicator of good animal welfare. From a management perspective, on the other hand, it is important to determine what causes a weak oestrus display. 
Lameness also constrains oestrous signalling (Manske et al., 2002; Sood and Nanda, 2006; Walker et al., 2008). Therefore, with the clearly higher odds of pregnancy-to-term in not-lame animals, and considering that pregnancy and calving rates were clearly related to intensity of oestrus signs, it is pertinent to speculate that lameness might well have affected pregnancy by way of a lower oestrous display also in the studied herd, even if differences in oestrous intensity were not fully attained.

Although pregnancy and calving rates were acceptable for heifers (72\% and 64\%, respectively), they were rather low for cows (37\% and 33\%), also explained partly by a high milk production (Rodriguez-Martinez et al., 2008). Lameness is another possible cause of the poor pregnancy results of the studied cows, mediated by weak oestrus signs and bad timing of the AI, although no significant association between lameness and oestrus intensity was found. While fertilization rates can reach $85-90 \%$, calving rates are mostly below $40 \%$ in the

245 Holstein breed, some authors reporting calving rates down to 25\% (Diskin, 2008b; RodriguezMartinez et al., 2008). Despite the fact that four heifers - three of them of the SH breed suffered abortions, the calving results in the present study do not seem to be as poor, especially not for heifers. Whether differences in genetic selection between Scandinavia and other regions/countries lay behind the relatively high calving rates for heifers in this herd, remains to be determined (see Rodriguez-Martinez et al., 2008). On the other hand, the low rates depicted by the studied cows deserves attention and further investigation, because it could be argued that both AI timing and lameness have an important negative impact on pregnancy, and as a consequence, contribute to impaired animal welfare. Simply adding another period of observations in the afternoon/evening (e.g. before gathering cows to the night milking) and re-evaluating the AI routine would probably help improve pregnancy rates in both cows and heifers (see Rodriguez-Martinez et al., 2008, and references therein). 


\section{Conclusions}

260 The odds of pregnancy-to-term are several times higher when standing oestrus is observed than when animals display only secondary oestrous signs. Lame cows have a several times lower odds of pregnancy/calving than not-lame cows. Further research is needed to study relations between performance and animal welfare, including factors that influence oestrous intensity.

\section{Acknowledgements}

The authors wish to thank the staff of Nötcenter Viken (Falköping, Sweden) for assistance during the collection of data. We also thank Dr. Telmo Nunes and Dr. Filipa Baptista for their valuable suggestions on the statistical analyses.

\section{References}

Bell, N., Bell, M., Knowles, T., Whay, H., Main, D., Webster, A., 2009. The development, implementation and testing of a lameness control programme based on HACCP principles and designed for heifers on dairy farms. Vet. J. 180, 178-188.

Cutullic, E., Delaby, L., Causeur, D., Michel, G., Disenhaus, C., 2009. Hierarchy of factors affecting behavioural signs used for oestrus detection of Holstein and Normande dairy cows in a seasonal calving system. Anim. Reprod. Sci. 113, 22-37.

280 Diskin, M., 2008a. Reproductive management of dairy cows: A review (part I). Irish Vet. J. $61,326-332$.

Diskin, M., 2008b. Reproductive management of dairy cows: A review (part II). Irish Vet. J. $61,403-411$. 
Edmonson, A., Lean, I., Weaver, L., Farver, T., Webster, G., 1989. A body condition scoring chart for Holstein dairy cows. J. Dairy Sci. 72, 68-78.

European Food Safety Authority (EFSA), 2009a. Scientific Opinion of the Panel on Animal Health and Welfare on a request from the Commission on the risk assessment of the impact of housing, nutrition and feeding, management and genetic selection on leg and locomotion problems in dairy cows. EFSA J. 1142, 1-57.

290 European Food Safety Authority (EFSA), 2009b. Scientific report of EFSA prepared by the Animal Health and Animal Welfare Unit on the effects of farming systems on dairy cow welfare and disease. Annex to EFSA J. 1143, 1-284.

Farm Animal Welfare Council, 1997. Report on the Welfare of Dairy Cattle. Ministry of Agriculture, Fisheries and Food, Surbiton, Surrey, UK. Retrieved June 5, 2009 from http://www.fawc.org.uk/reports/dairycow/dcowr081.htm.

Farm Animal Welfare Council, 2009. Farm Animal Welfare Council: Five freedoms. Retrieved June 5, 2009, from http://www.fawc.org.uk/freedoms.htm.

Ferguson, J., Azzaro, G., Licitra, G., 2006. Body condition assessment using digital images. J. Dairy Sci. 89, 3833-3841.

300 Forster, K., Galina, C., Maquivar, M., van der Laan, G., Arnoni, R., Verduzco, A., 2007. Assessment of the intensity of behavioural traits and ovulation between synchronized and non-synchronized cows. Reprod. Domest. Anim. 42, 566-570.

Hallén Sandgren, C., Lindberg, A., Keeling L., 2009. Using a national dairy database to identify herds with poor welfare. Anim. Welfare 18, 523-532.

305 Haskell, M., Rennie, L., Bowell, V., Bell, M., Rutherford, K., Lawrence, A., 2005. Housing, management, level of production and dairy cow welfare. Desafios Actuais e Futuros da Vaca Leiteira de Alta Produção, Vairão, Porto, Portugal, January 7, 2005. Retrieved 12 June 12, 2009, from http://home.utad.pt/ cecav/vacaleiteira/Comunicacoes/Mhaskell.pdf. 
Hultgren, J., Manske, T., Bergsten, C., 2004. Associations of sole ulcer at claw trimming with reproductive performance, udder health, milk yield, and culling in Swedish dairy cattle. Prev. Vet. Med. 62, 233-251.

International Dairy Federation, 2008. The world dairy situation 2008. Bulletin of the IDF, 432/2008. Brussels: IDF.

Manske, T., Hultgren, J., Bergsten, T., 2002. Prevalence and interrelationships of hoof lesions and lameness in Swedish dairy cows. Prev. Vet. Med. 54, 247-263.

Murphy, M., 2004. Making the most of grass-based forages in diet formulation. Adv. Dairy Tech. 16, 205-215.

Nötcenter Viken, 2009. Avelsarbetet på Viken (Breeding strategies at Viken) Retrieved April 2, 2009, from http://www.notcenterviken.se/avelsarbetet.asp

320 Oltenacu, P., Algers, B., 2005. Selection for increased production and the welfare of dairy cows: Are new breeding goals needed? Ambio 34, 311-315.

Pérez-Marín, C., España, F., 2007. Oestrus expression and ovarian function in repeat breeder cows, monitored by ultrasonography and progesterone assay. Reprod. Domest. Anim. 42, $449-456$.

325 Rodriguez-Martinez, H., Hultgren, J., Båge, R., Bergqvist, A-S., Svensson, C., Bergsten, C., Lidfors, L., Gunnarsson, S., Algers, B., Emanuelson, U., Berglund, B., Andersson, G., Håård, M., Lindhé, B., Stålhammar, H., Gustafsson, H., 2008. Reproductive performance in high-producing dairy cows: Can we sustain it under current practice? In International Veterinary Information Service, IVIS (Ed.), IVIS Reviews in Veterinary Medicine, Ithaca NY (www.ivis.org), R0108.1208 (Open Journal). Retrieved February 25, 2009, from http://www.ivis.org/reviews/rev/rodriguez/chapter.asp?LA=1.

Roelofs, J., 2005. When to inseminate the cow? Insemination, ovulation and fertilization in dairy cattle. Ph.D. Thesis. Wageningen University, Wageningen, The Netherlands. 
Sood, P., Nanda, A., 2006. Effect of lameness on estrous behavior in crossbred cows. 335 Theriogenology 66, 1375-1380.

van Eerdenburg, F., Karthaus, D., Taverne, M., Merics, I., Szenci O., 2002. The relationship between estrous behavioral score and time of ovulation in dairy cattle. J. Dairy Sci. 85, $1150-1156$.

Walker, S., Smith, R., Jones, D., Routly, J., Dobson, H., 2008. Chronic stress, hormone 340 profiles and estrus intensity in dairy cattle. Horm. Behav. 53, 493-501.

Welfare Quality®, 2009. Welfare Quality® assessment protocol for cattle. Report. Welfare Quality® Consortium, Lelystad, The Netherlands.

Yoshida, C., Nakao, T., 2005. Some characteristics of primary and secondary oestrous signs in high-producing dairy cows. Reprod. Domest. Anim. 40, 150-155. 
Table 1. Distribution of heifers and first-parity cows disclosed by breed, age, body condition score and prevalence of lameness (means \pm SD) in a Swedish nucleus dairy herd studied during 2009.

\begin{tabular}{|l|c|c|c|c|c|}
\hline \multirow{2}{*}{ Animal category } & \multicolumn{2}{|c|}{$\begin{array}{c}\text { Breed } \\
\text { (\%, frequency) }\end{array}$} & $\begin{array}{c}\text { Age } \\
\text { (mo, range) }\end{array}$ & $\begin{array}{c}\text { Body condition } \\
\text { score } \\
\text { (points, range) }\end{array}$ & ( $\begin{array}{c}\text { Lameness } \\
\text { (\%, frequency) }\end{array}$ \\
\cline { 2 - 3 } & $\begin{array}{c}\text { Swedish } \\
\text { Holstein }\end{array}$ & $\begin{array}{c}\text { Swedish } \\
\text { Red }\end{array}$ & & & \\
\hline Heifers & $49 \%^{\mathrm{a}}(18 / 37)$ & $51 \%^{\mathrm{a}}(19 / 37)$ & $18 \pm 2.2^{\mathrm{a}}(15-24)$ & $3.4 \pm 0.4^{\mathrm{a}}(2.5-4)$ & $3^{\mathrm{a}}(1 / 35)$ \\
\hline First parity cows & $57 \%^{\mathrm{a}}(17 / 30)$ & $43 \%^{\mathrm{a}}(13 / 30)$ & $33.5 \pm 7.0^{\mathrm{b}}(27-55)$ & $2.8 \pm 0.4^{\mathrm{b}}(2-3.5)$ & $59^{\mathrm{b}}(16 / 27)$ \\
\hline
\end{tabular}

${ }^{\mathrm{a}-\mathrm{b}}$ Different superscripts differ significantly between animal categories, $P<0.01$ (Fisher's exact test or $t$-test). 


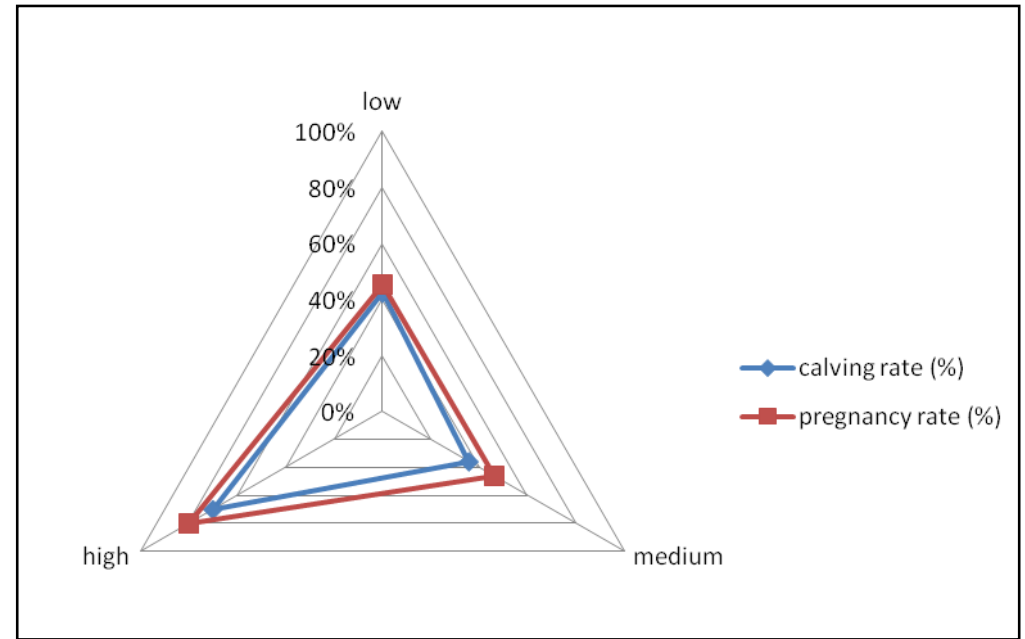

Figure 1. Radar plot showing the relationship between levels of oestrous intensity (low, medium, or high) and pregnancy and calving rates in a Swedish nucleus dairy herd studied during 2009.

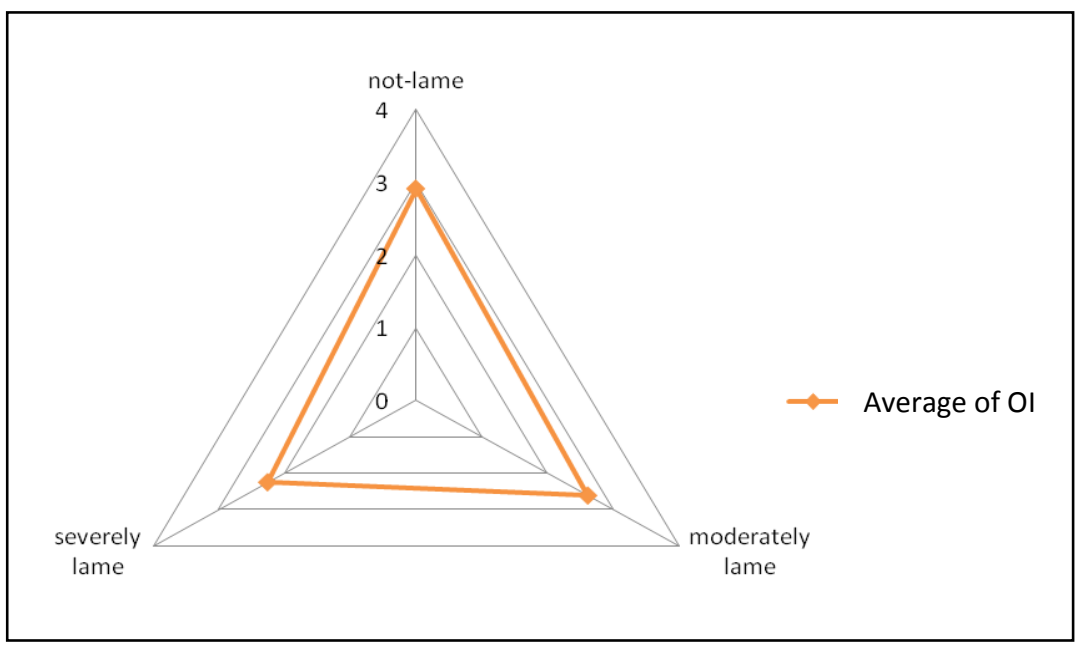

Figure 2. Radar plot showing the relationship between lameness intensity (non-lame, moderately or severely lame) and average oestrus intensity (OI; $2=l o w, 3=$ medium, 4=high) in a Swedish nucleus dairy herd studied during 2009.

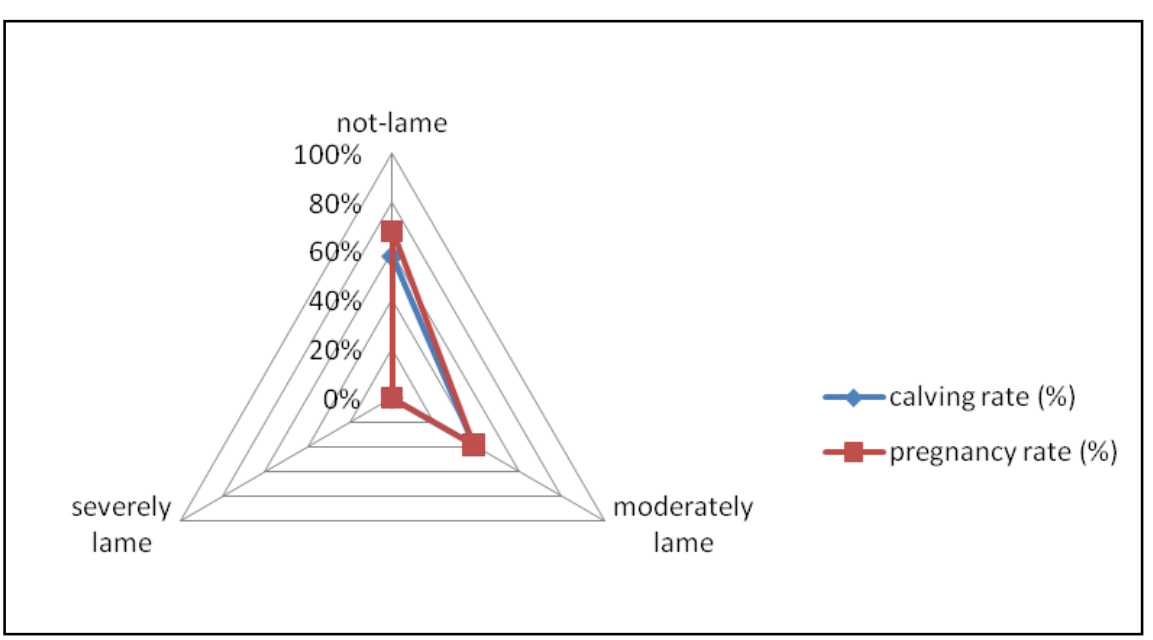

Figure 3. Radar plot showing the relationship between lameness intensity (not-lame, moderately or severely lame) and pregnancy and calving rates in a Swedish nucleus dairy herd studied during 2009. 